\title{
EFEITO DE DIFERENTES TEMPOS DE COZIMENTO NOS TEORES DE MINERAIS EM FOLHAS DE BRÓCOLIS, COUVE-FLOR E COUVE (Brassica oleracea L.) ${ }^{1}$
}

\author{
MÔNICA ALESSANDRA TEIXEIRA DOS SANTOS ${ }^{2}$ \\ CELESTE MARIA PATTO DE ABREU ${ }^{3}$ \\ VÂNIA DÉA DE CARVALHO ${ }^{4}$
}

RESUMO - Foram determinados os teores de fósforo, cálcio, potássio, magnésio e ferro das folhas de brócolis, couve-flor e folhas de couve. Os materiais estudados foram cultivados no município de Ijaci, MG, em diferentes tempos de cozimento (0, 2, 4, 6, 8 e 10 minutos), com o objetivo de verificar a utilização total dessas brássicas na alimentação humana, as quais são ricas fontes de minerais. Pelos resultados, constatou-se que as folhas de couve-flor, base úmida, superaram as demais variedades na maioria dos minerais analisados. No entanto, a água de cozimento reduziu o teor de minerais em todas as variedades avaliadas.

TERMOS PARA INDEXAÇÃO: Minerais, folhas, brócolis, couve-flor, couve, cozimento, Brassica spp.

\section{EFFECT OF DIFFERENT BOILING TIMES ON CONTENTS OF MINERALS IN LEAVES OF BROCCOLI, CAULIFLOWER AND CABBAGE (Brassica oleracea L.)}

\begin{abstract}
The contents of phosphorus, calcium, potassium, magnesium and iron in leaves of broccoli, cauliflower and cabbage submitted to boiling for different times $(0,2,4,6,8$ and 10 minutes) were determined. The
\end{abstract}

results revealed that the cauliflower leaves, on fresh weight basis, overcame the other varieties in most of the analyzed minerals. However, boiling water caused removal of minerals in all the varieties evaluated.

INDEX TERMS: Minerals, leaves, broccoli, cauliflower, cabbage, boiling, Brassica spp.

\section{INTRODUÇÃO}

A desnutrição é um problema sério em todo o mundo. Ela afeta os grupos mais vulneráveis da população, principalmente crianças menores de cinco anos que vivem na pobreza em países pouco desenvolvidos.

Em pesquisas realizadas na América Latina, verificou-se que a deficiência de ferro é um problema de saúde pública em muitos países, principalmente entre as classes menos favorecidas (Portugal, 1984).

Os minerais são necessários ao organismo em quantidades que variam de gramas a miligramas, sendo essenciais para o desempenho de diversas funções e são adquiridos através de dieta. A deficiência de um ou mais componentes minerais pode resultar em gra- ves distúrbios orgânicos, tais como a osteoporose, bócio e anemia.

Os resíduos de frutas, verduras e legumes não constituem o cardápio alimentar da maioria das populações, além de serem descartados em grandes quantidades pelas indústrias alimentícias. Pesquisas revelam que os resíduos vegetais são importantes fontes de nutrientes e poderiam ser aproveitados como uma forma econômica de solucionar o problema da fome e desnutrição das populações carentes.

Pouca atenção é destinada às partes vegetativas de algumas espécies de hortaliças consideradas de alto valor nutritivo. Vegetais crucíferos (família Brassicaceae), como o brócolis e a couve-flor, em que o consumo se limita às suas inflorescências, poderiam ser integralmente utilizados na alimentação humana.

1. Parte da dissertação apresentada à UNIVERSIDADE FEDERAL DE LAVRAS/UFLA, Caixa Postal 37 - 37200 000 - Lavras, MG, pelo primeiro autor, para obtenção do título de Mestre em Ciência dos Alimentos.

2. Mestre em Ciência dos Alimentos pela UFLA.

3. Engenheiro Agrônomo, DS. Ciência dos Alimentos, Professora Adjunto do Departamento de Química da UFLA.

4. Engenheiro Agrônomo, DS. Ciência dos Alimentos, Professora Adjunto do Departamento de Ciência dos Alimentos da UFLA. 
Krause \& Mahan (1991) citam os vegetais verdes, como o repolho-crespo, folhas de mostarda e brócolis como importantes fontes de cálcio e são excelentes fontes de ferro e magnésio.

Segundo Nieuwhof (1969), o cálcio ocorre abundantemente nas folhas verdes, como a couve, que está entre os vegetais com o conteúdo mais elevado desse mineral. A couve-flor possui baixo teor de cálcio, contendo menos de um décimo da quantia que ocorre nas couves, ao passo que as outras brássicas ocupam posições intermediárias.

Em relação ao fósforo, a maioria dos vegetais, incluindo as culturas de brássicas, possui baixos teores desse mineral.

\section{MATERIAL E MÉTODOS}

Este trabalho foi desenvolvido no Departamento de Ciência dos Alimentos e Departamento de Química da Universidade Federal de Lavras (UFLA). Foram utilizadas folhas de brócolis, couve-flor e couve comum, colhidas numa propriedade agrícola rural do município de Ijaci, Minas Gerais. As folhas foram colhidas pela manhã, lavadas em água corrente e posteriormente em água destilada. Em seguida, foram picadas uniformemente e, após secas à temperatura ambiente, foram submetidas à cocção (temperatura de ebulição) por seis diferentes tempos $(0,2,4,6,8$ e 10 minutos), com 3 repetições por tratamento, utilizando 4 litros de água destilada para cada $400 \mathrm{~g}$ de folhas Após a aplicação dos tratamentos, o material foi levado à estufa ventilada de $60^{\circ}$ até secagem total (peso constante), de acordo com a AOAC (1990). O material seco foi triturado em moinho de facas e homoge- neizado para posterior realização das análises. Os resultados foram expressos em base úmida e seca.

Os teores de fósforo, potássio, cálcio, magnésio e ferro foram determinados segundo Sarruge \& Haag (1974) e Malavolta et al. (1989). Os extratos foram obtidos por digestão nitroperclórica. O fósforo foi determinado por colorimetria, segundo método da AOAC (1990); o cálcio, magnésio e ferro, por espectrofotometria de absorção atômica, e o potássio, por fotometria de chama.

$\mathrm{O}$ experimento foi realizado em delineamento casualizado, em esquema fatorial 3x6 (folhas de 3 espécies de brássicas x 6 tempos de cozimento) e 3 repetições.

\section{RESULTADOS E DISCUSSÃO}

De acordo com a Figura 1, as folhas de couveflor apresentaram os maiores teores de fósforo, com $59,4 \mathrm{mg}$ em $100 \mathrm{~g}$ de material fresco, suprindo 7,43\% das necessidades de $800 \mathrm{mg} /$ dia para adultos de 25 a 50 anos, segundo o NRC (1989). Os resultados encontrados assemelham-se a vegetais não convencionais, como a taioba $(50 \mathrm{mg} / 100 \mathrm{~g}$, citado por Pinto, 1998) e parte aérea de cenoura e beterraba $(35,14$ e 48 mg/100 g, respectivamente) (Sartorelli, 1998).

Não foram encontradas diferenças significativas nos teores de fósforo no material seco das espécies estudadas.

Verifica-se na Figura 2 o comportamento do fósforo no material fresco durante a aplicação dos tratamentos. Os teores desse mineral sofreram uma pequena queda à medida que aumentou o tempo de fervura, o que significa que esse mineral pode ter sido arrastado pela água de cozimento.

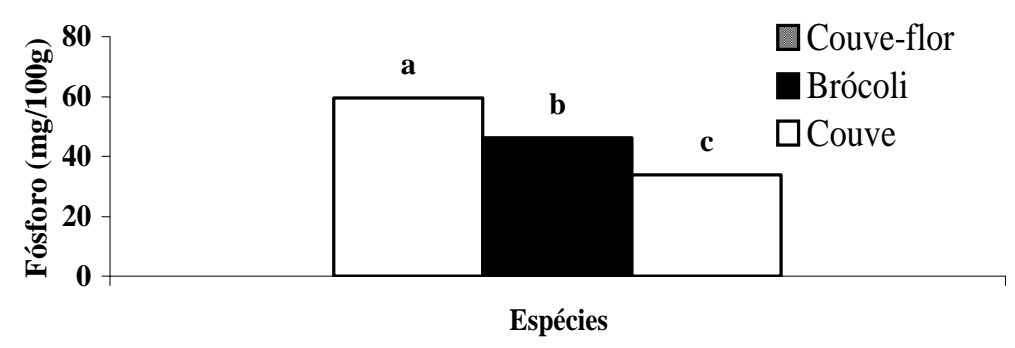

FIGURA 1 - Teores médios de fósforo $(\mathrm{mg} / 100 \mathrm{~g})$ das três espécies de brássicas, expressos em matéria úmida. Barras com mesma letra não diferem entre si a $1 \%$ de probabilidade. 


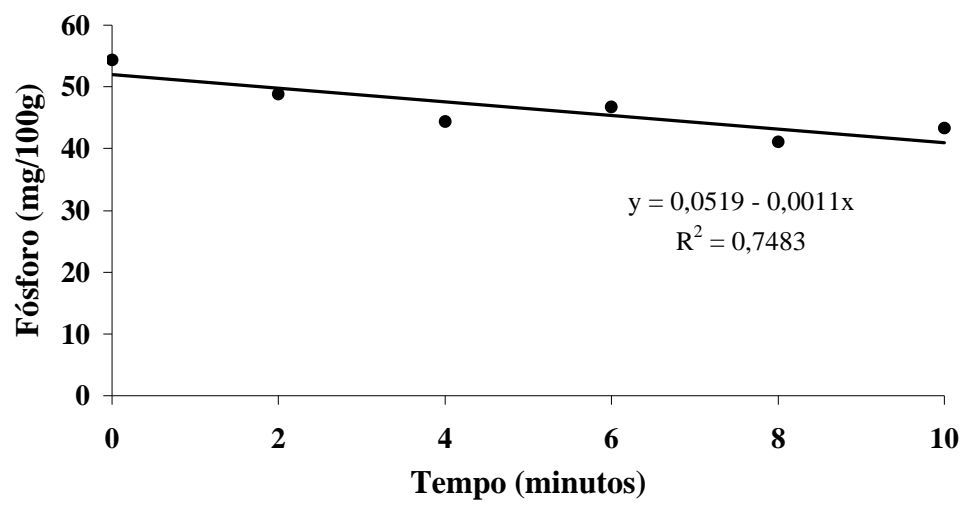

FIGURA 2 - Curva e equação de regressão representativas dos teores médios de fósforo (mg/100 g) das três espécies de brássicas durante seis tempos de cozimento, expressos em matéria úmida.

O teor médio de cálcio foi mais elevado nas folhas de couve-flor, alcançando nível de $509,4 \mathrm{mg} / 100 \mathrm{~g}$ do material fresco; nas folhas de brócolis e couve, os níveis foram de 426,7 e $301,7 \mathrm{mg} / 100 \mathrm{~g}$, respectivamente (Figura 3).

Nieuwhof (1969) encontrou 200 a $329 \mathrm{mg} / 100 \mathrm{~g}$ de cálcio na folha de couve e Franco (1992) encontrou $400 \mathrm{mg} / 100 \mathrm{~g}$ de cálcio em brócolis cru, valores próximos aos encontrados no presente trabalho.

Cabe ressaltar que os teores de minerais encontrados na literatura para couve-flor e brócolis foram extraídos da inflorescência dessas espécies e não de suas folhas. Os resultados de cálcio obtidos das folhas de brócolis analisadas são semelhantes aos das inflorescências. A couve-flor possui em suas inflorescências 20 a $22 \mathrm{mg} / 100 \mathrm{~g}$ de cálcio, segundo Nieuwhof (1969). No presente trabalho, verifica-se que suas folhas apresentam maiores teores de cálcio, sendo, portanto, melhores fontes desse mineral.

A ingestão diária de cálcio recomendada para indivíduos adultos de 25 a 50 anos é de $800 \mathrm{mg}$, segundo o NRC (1989). De acordo com os resultados das folhas estudadas, observa-se que, no material úmido, as folhas de couve-flor, brócolis e couve contribuem, respectivamente, com $63,7 \%, 53,3 \%$ e $37,7 \%$ do cálcio recomendado.

Não foram encontradas diferenças significativas nos teores de cálcio do material seco das espécies avaliadas.

Na Figura 4 verifica-se o comportamento do cálcio das folhas úmidas e secas submetidas aos diferentes tempos de fervura. As folhas úmidas praticamente mantiveram seus teores de cálcio à medida que o tempo de cozimento foi aumentado. O material seco apresentou uma ligeira queda, perdendo $25,33 \%$ do teor original de cálcio.

Observa-se, na Figura 5, que a couve-flor e a couve não diferenciaram significativamente entre si quanto aos teores de potássio na matéria úmida, apresentando as maiores médias, com 258,3 e $235 \mathrm{mg} / 100 \mathrm{~g}$, respectivamente. $\mathrm{O}$ brócolis atingiu a menor média (130 $\mathrm{mg} / 100 \mathrm{~g}$ ).

Kawashima (1997), avaliando os teores minerais em algumas hortaliças (alface, agrião, rúcula, couve, couve-chinesa, escarola e repolho), concluiu que o nível de potássio é o mais alto entre todos os elementos e contrasta principalmente com os teores de sódio, que são muito baixos. Segundo a autora, a hortaliça que possui maiores teores de potássio é a couve, e afirma ainda que teores elevados de potássio são um fato esperado em hortaliças e frutas.

De acordo com Franco (1986), para cada 100g de couve, espinafre, taioba, banana-prata e laranja, têmse $258 \mathrm{mg}, 490 \mathrm{mg}, 591 \mathrm{mg}, 370 \mathrm{mg}$ e $156,6 \mathrm{mg}$ de potássio, respectivamente.

De acordo com a Figura 6, as espécies de brássicas, material úmido, com teores médios de potássio de $312,4 \mathrm{mg}$, ao 0 minuto de fervura, atingiram teores de 103,2 mg após 10 minutos, perdendo cerca de $66,97 \%$ do potássio presente inicialmente, comportamento que pode ser explicado pela lixiviação do mineral durante o cozimento das hortaliças. 


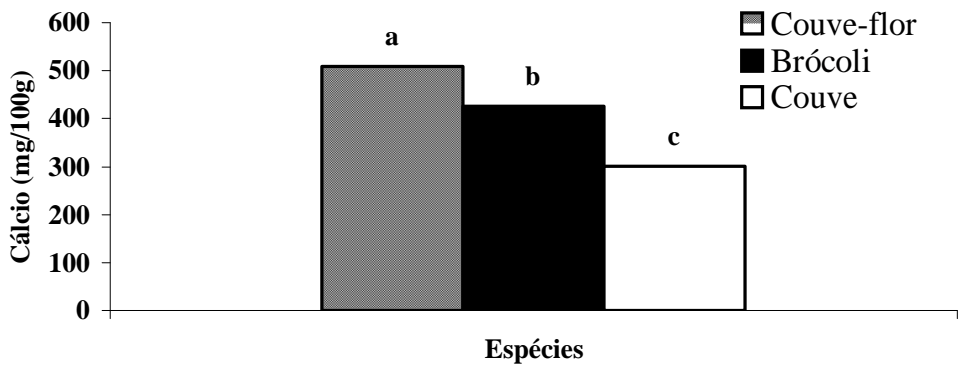

FIGURA 3 - Teores médios de cálcio $(\mathrm{mg} / 100 \mathrm{~g})$ das três espécies de brássicas, expressos em matéria úmida. Barras com mesma letra não diferem entre si a $5 \%$ de probabilidade.

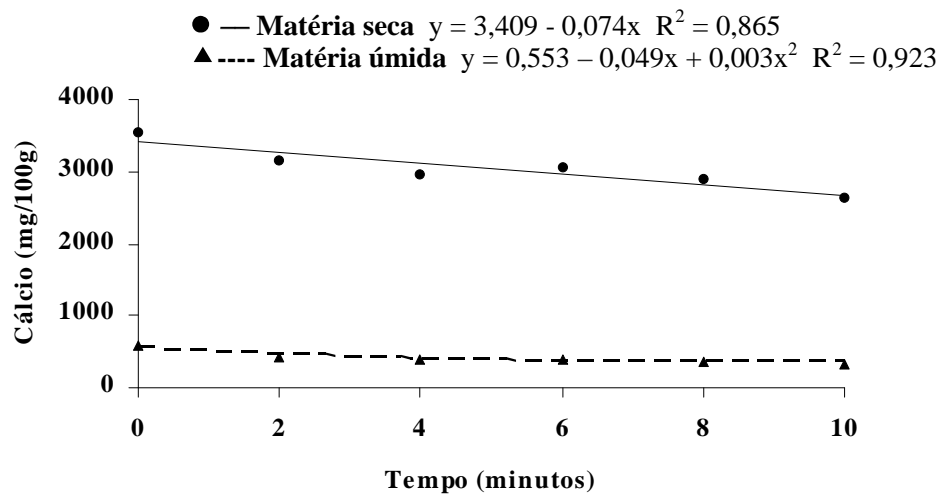

FIGURA 4 - Curvas e equações de regressão representativas dos teores médios de cálcio (mg/100 g) das três espécies de brássicas no material úmido e seco, durante seis tempos de cozimento.

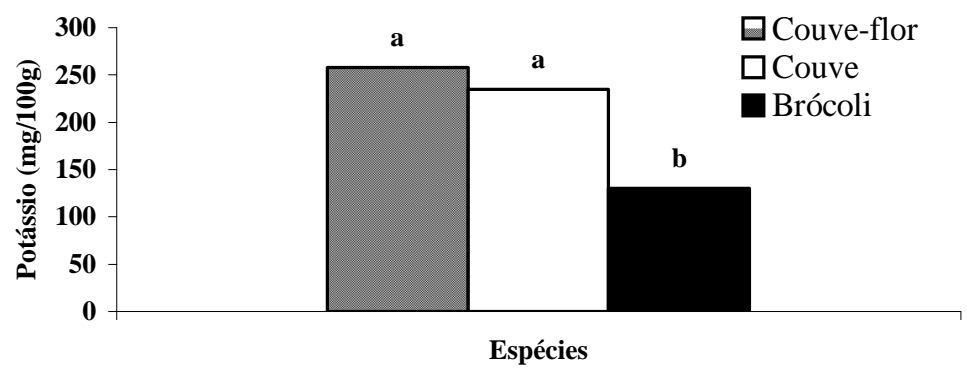

FIGURA 5 - Teores médios de potássio $(\mathrm{mg} / 100 \mathrm{~g})$ das três espécies de brássicas, expressos em matéria úmida. Barras com mesma letra não diferem entre si a $1 \%$ de probabilidade. 


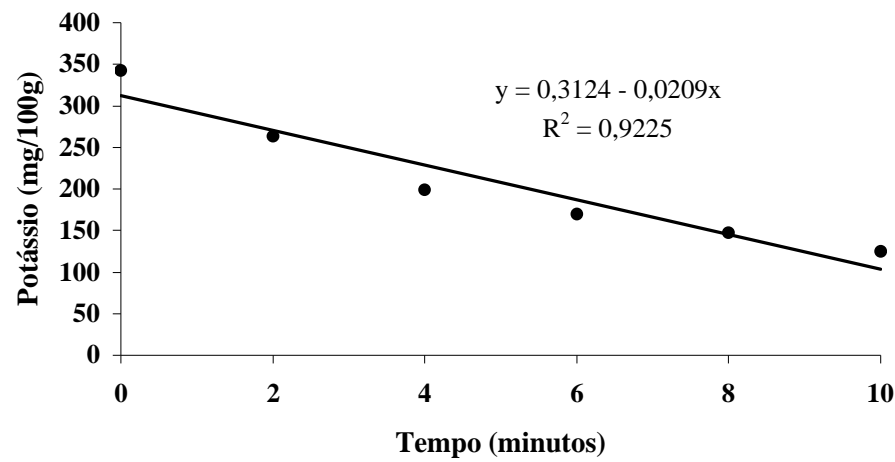

FIGURA 6 - Curva e equação de regressão representativas dos teores médios de potássio (\%) das três espécies de brássicas, durante seis tempos de cozimento, expressos em matéria úmida.

No material seco, os teores de potássio apresentaram diferenças significativas entre os dois fatores estudados, ou seja, espécies de brássicas e tempo de cozimento (Figura 7). Observa-se que a couve, com o maior teor do mineral, obteve maior queda, perdendo cerca de $56,5 \%$ do potássio presente antes da fervura. A couve-flor apresentou médias intermediárias, com pequena perda do mineral após 10 minutos de fervura. $\mathrm{O}$ brócolis obteve o menor teor de potássio, com 1560 $\mathrm{mg} / 100 \mathrm{~g}$, apresentando perda de $27,13 \%$ do seu conteúdo após aplicação dos tratamentos. Entretanto, a couve ainda manteve o maior teor desse mineral após os $10 \mathrm{mi}-$ nutos de fervura, quando comparada às outras duas espécies. Segundo Tannembaum et al. (1993), a principal operação que origina perdas de substâncias minerais é a lixiviação, que arrasta parte dos minerais solúveis.

Na Figura 8 encontram-se os teores de magnésio das três espécies estudadas em base seca. É possível observar que elas diferem significativamente entre si; os teores do mineral encontrados em $100 \mathrm{~g}$ de material foram de 292,2 mg para a couve, 192,8 mg para o brócolis e $154,4 \mathrm{mg}$ para a couve-flor.

A couve-flor, apesar de apresentar os menores teores de magnésio, superou algumas importantes fontes do mineral, como farelo de trigo integral (120 $\mathrm{mg} / 100 \mathrm{~g})$, leite de vaca em pó $(90 \mathrm{mg} / 100 \mathrm{~g})$ e lentilha seca $(80 \mathrm{mg} / 100 \mathrm{~g})$, segundo tabela de Franco (1986).

Kawashima (1997), estudando os teores minerais de hortaliças, como alface, agrião, rúcula, couve, couvechinesa, escarola e repolho, verificou que, além do potássio, a couve é a hortaliça que possui maiores teores de magnésio e cálcio.
Na Figura 9 verifica-se o comportamento dos teores de magnésio durante os tempos de cozimento do material úmido e seco. Na matéria úmida, o mineral apresentou um comportamento quase uniforme, com uma pequena queda até 8 minutos de fervura. Os teores de magnésio presentes na matéria seca das espécies avaliadas caíram consideravelmente; $61,84 \%$ do magnésio foram perdidos na água de cozimento.

Os teores médios do microelemento ferro encontrados nas três espécies estudadas, em $100 \mathrm{~g}$ do material úmido, foram: 2,67 $\mathrm{mg}$ na couve-flor, $1,72 \mathrm{mg}$ no brócolis e $0,80 \mathrm{mg}$ na couve, conforme Figura 10.

Comparando os teores de ferro encontrados por Nieuwhof (1969) nas inflorescências de brócolis (1,3 $\mathrm{mg} / 100 \mathrm{~g})$ e couve-flor $(0,5 \mathrm{a} 1,1 \mathrm{mg} / 100 \mathrm{~g})$, observa-se que as folhas dessas espécies, analisadas em base úmida, contribuem com uma maior quantidade desse microelemento.

No material seco, a couve-flor superou as demais espécies, com 16,32 mg, suprindo as exigências diárias recomendadas pelo NRC (1989), que é de $10 \mathrm{mg}$ para homens adultos.

A couve-flor destaca-se por possuir teores de ferro superiores na matéria seca, aos encontrados em $100 \mathrm{~g}$ de fígado de boi $(12,1 \mathrm{mg})$, folhas de mandioca $(7,60$ $\mathrm{mg}$ ) e gema de ovo $(5,87)$, alimentos considerados importantes fontes de ferro (Franco, 1986).

Com o aumento do tempo de cozimento, as folhas úmidas analisadas tiveram seus teores de ferro diminuídos, mostrando a tendência de lixiviação dos minerais por contato com a água (Figura 11).

Os teores de ferro não diferenciaram significativamente com o aumento do tempo de fervura para as folhas secas. 


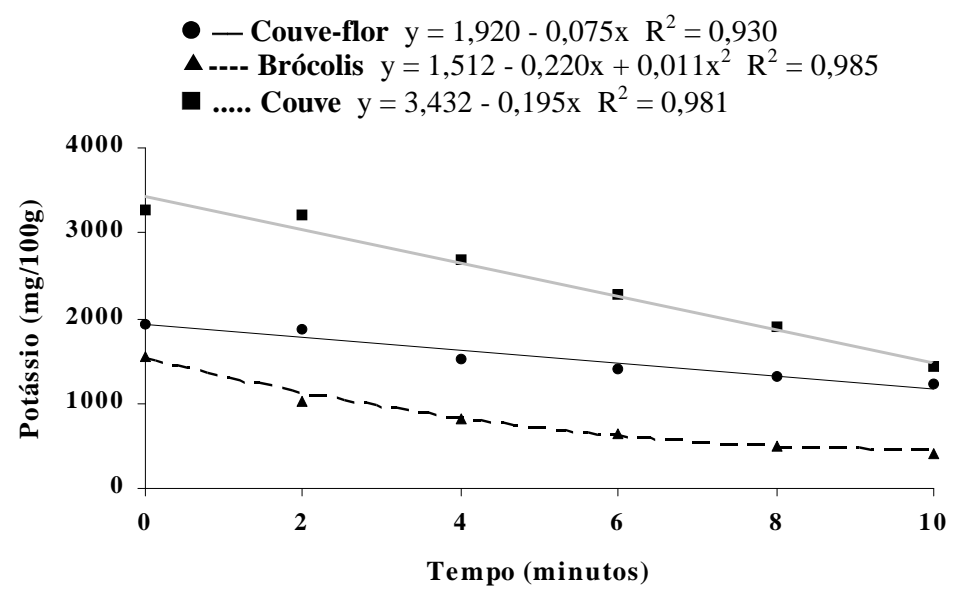

FIGURA 7 - Curvas e equações de regressão representativas dos teores médios de potássio (mg/100 g) das três espécies de brássicas, submetidas a seis tempos de cozimento, expressos em matéria seca.

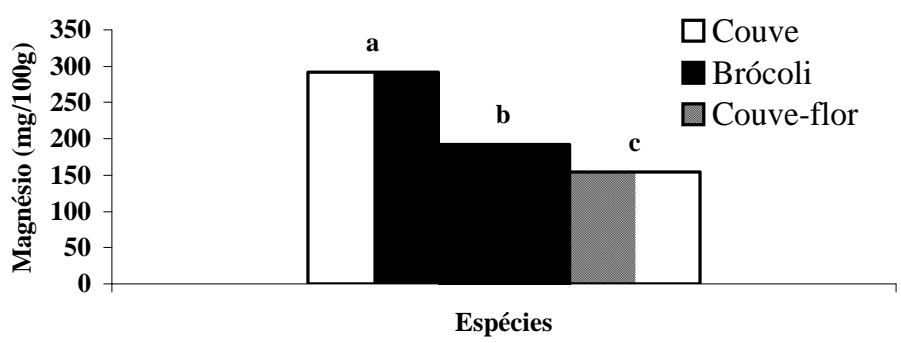

FIGURA 8 - Teores de magnésio $(\mathrm{mg} / 100 \mathrm{~g})$ das três espécies de brássicas, expressos em matéria seca. Barras com mesma letra não diferem entre si a $1 \%$ de probabilidade.

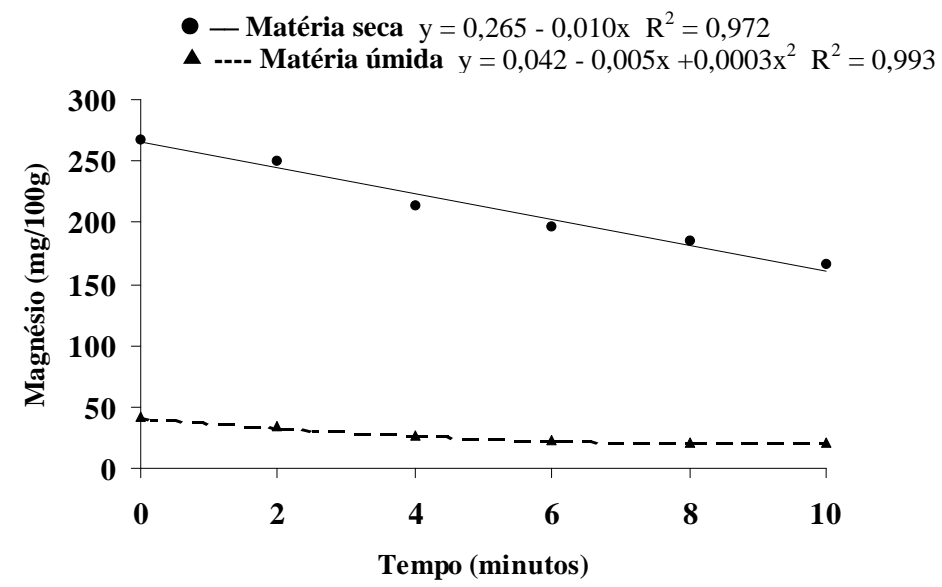

FIGURA 9 - Curvas e equações de regressão representativas dos teores médios de magnésio (mg/100 g) das três espécies de brássicas no material úmido e seco, durante seis tempos de cozimento. 


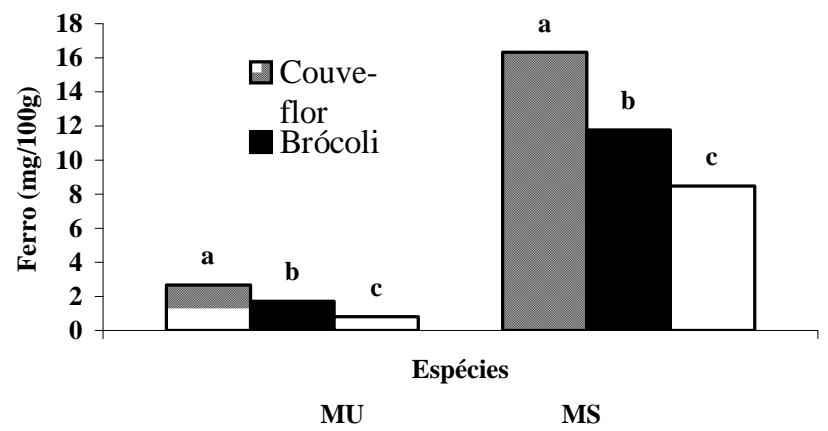

FIGURA 10 - Teores médios de ferro (mg/100 g) das três espécies de brássicas, expressos em matéria úmida (MU) e seca (MS). Barras com mesma letra não diferem entre si a $1 \%$ de probabilidade.

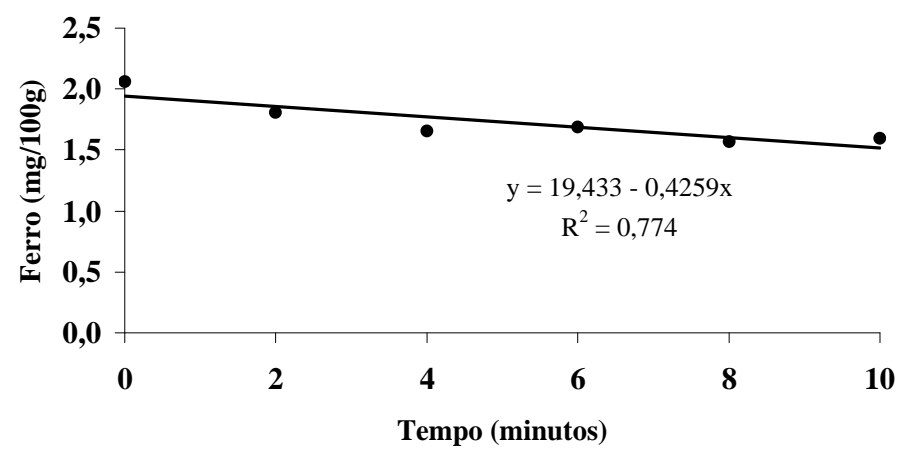

FIGURA 11 - Curva e equação de regressão representativas dos teores médios de ferro (mg/100 g) das três espécies de brássicas durante seis tempos de cozimento, expressos em matéria úmida.

\section{CONCLUSÕES}

Todos os minerais avaliados tiveram seus teores diminuídos com o aumento do tempo de cozimento, mostrando terem sido removidos pela água; no entanto, mesmo após a fervura, as folhas das espécies estudadas mantiveram teores satisfatórios de minerais, podendo ser utilizadas na suplementação de dietas. Em base úmi$\mathrm{da}$, a couve-flor destacou-se com os maiores teores de fósforo, cálcio, potássio e ferro.

\section{REFERÊNCIAS BIBLIOGRÁFICAS}

ASSOCIATION OF OFFICIAL ANALYTICAL CHEMISTS. Official methods of analysis. 15. ed. Washington, 1990. v. 2.

FRANCO, G. Tabela de composição química dos alimentos. 7. ed. Rio de Janeiro: Atheneu, 1986. 145 p.
FRANCO, G. Tabela de composição química dos alimentos. 8. ed. São Paulo: Atheneu, 1992. 230 p.

KAWASHIMA, L. M. Teores totais e frações solúveis de alguns elementos minerais nutricionalmente importantes em hortaliças folhosas e efeito do cozimento sobre solubilidade e perdas. 1997. $107 \mathrm{f}$. Dissertação (Mestrado em Engenharia de Alimentos) - Universidade Estadual de Campinas, Campinas.

KRAUSE, M. V.; MAHAN, L. K. Alimentos, nutrição e dietoterapia. Tradução de R. A. Almeida et al. São Paulo: Roca, 1991. 981 p. Título original: Food, nutrition and diet therapy.

MALAVOLTA, E.; VITTI, G. C.; OLIVEIRA, S. A. Avaliação de estado nutricional das plantas. Piracicaba: Potafos, 1989. 201 p.

Ciênc. agrotec., Lavras. V.27, n.3, p.597-604, maio/jun., 2003 
NATIONAL RESEARCH COUNCIL. Recommended dietary allowances. 10. ed. Washington: National Academic, 1989. 284 p.

NIEUWHOF, M. Cole crops: botany, cultivation and utilization. London: Leonard Hill, 1969. 353 p.

PINTO, N. A. V. D. Avaliação química das folhas, limbos e caules da taioba (Xanthosoma sagittifolium $\mathrm{S}$ chott), visando seu aproveitamento na alimentação humana. 1998. 88 p. Dissertação (Mestrado em Ciência dos Alimentos) - Universidade Federal de Lavras, Lavras.

PORTUGAL, F. Vitaminas: nutrição e terapia I-receita: informativo sobre nutrição humana - Roche. Geográfica Universal, Rio de Janeiro, n. 29, p. 29, jan. 1984.

SARRUGE, J. R.; HAAG, H. P. Análise química em plantas. Piracicaba: ESALQ/USP, 1974. 56 p.
SARTORELLI, C. S. C. Caracterização química da parte aérea de cenoura (Dacus carota) e beterraba (Beta vulgaris), visando ao aproveitamento na alimentação humana. 1998. 98 p. Dissertação (Mestrado em Ciência dos Alimentos) - Universidade Federal de Lavras, Lavras.

TANNENBAUM, S. R.; YOUNG, V. R.; ARCHER, M. C. Vitaminas y mirerales. In: FENNEMA, O. R. Química de los alimentos. 2. ed. Zaragoza: Acribia, 1993. cap. 7, p. 537-613. 